\title{
DIAGNÓSTICOS DE ENFERMAGEM EM CLIENTE COM (TCE) E EM SEU FAMILIAR E/OU PESSOA SIGNIFICATIVA
}

\author{
NURSING DIAGNOSIS FOR HEAD INUURY PATIENTS AND FOR RELATINE AND/OR \\ SIGNIFICANT PERSON
}

\author{
Anialcy Barbosa Faria ${ }^{1}$ \\ Isabel Cristina Fonseca da Cruz ${ }^{2}$
}

RESUMO: O presente trabalho tem por objetivo relatar o estudo de caso de um cliente com TCE e em seu familiar e/ou pessoa significativa, levantando os Diagnósticos de Enfermagem segundo a Taxonomia I da NANDA (North American Diagnosis Association), utilizando-se a Teoria das Necessidades Humanas Básicas Afetadas de Wanda Horta. O estudo foi realizado no Hospital Universitário Antonio Pedro, UFF, onde foram encontrados 6 diagnósticos de enfermagem para o cliente e 1 para 0 familiar.

UNITERMOS: Traumatismo crânio-encefálico - Família - Pessoa significativa - Diagnóstico de enfermagem.

\section{INTRODUÇÃO}

Partindo do princípio de que para assistir a qualquer tipo de cliente a formulação de diagnósticos de enfermagem é imprescindível, o estudo irá contribuir para implementar a assistência ao cliente com traumatismo crânioencefálico (TCE), familiar e/ou pessoa significativa deste.

O cliente, que é abordado neste estudo, é aquele cujo TCE foi causado por acidente de trânsito, e não foge à regra da surpresa de sua atual condição para si e para todos os que o rodeiam. A surpresa ocorre porque não é possível prever um acidente de trânsito que leva pessoas à hospitalização ou à morte. Com base em nossa experiência, a condição do acidentado, quando lúcido, ao dar entrada no Setor de Emergência, é de incredulidade acompanhada de inúmeros outros sentimentos.

As estatísticas demonstram que o cliente politraumatizado faz parte do dia a dia dos grandes hospitais, nas grandes cidades. Nos Estados Unidos, um cliente

\footnotetext{
${ }^{1}$ Enfermeira, Mestra em Enfermagem e Profa. Assistente da Escola de Enfermagem da Universidade Federal Fluminense (UFF).

${ }^{2}$ Enfermeira, Doutora em Enfermagem e Prof ${ }^{a}$ Titular da Escola de Enfermagem da UFF.
} 
morre de TCE a cada 12 minutos e mais de $75 \%$ dos TCE's sérios são atribuídos à alta velocidade dos veículos nos acidentes com automotores, que causam traumatismos translacionais severos que resultam em lacerações do tecido cerebral (Sheehy, Jimmerson, 1994).

O Brasil também possui índices elevados de acidentados, e estes são facilmente comprovados nos setores de emergência bem como nos noticiários e jornais. Em nosso país, mais precisamente em São Paulo, o trauma representa a primeira causa de morte na faixa etária de 4 a 49 anos de idade, responsável pela perda de maior número de anos de vida do que qualquer outra (Tacahaghi, 1994).

Os acidentes de trânsito com envolvimento de veículos a motor também foram responsáveis por cerca de $96 \%$ dos acidentes de transporte no município do Rio de Janeiro em 1980 (MS, 1983). A mortalidade por acidentes de trânsito pode ser observada entre os anos de 1980 e 1990, especialmente nos grupos de adultos jovens de 20 a 29 anos $(12,6)$ e nos mais velhos de 65 anos ou mais $(41,9)$ como a maior mortalidade no ano mais recente - 1990 , em todos os grupos etários (Klein, 1994).

Vermelho (1995), estudando a mortalidade de jovens nas cidades do Rio de Janeiro e São Paulo, aponta para a elevação dos coeficientes por violência principalmente no período de 1980 a 1991, destacando os acidentes de transporte e os homicídios como a primeira causa de morte em ambas as capitais e para o citado grupo. Em seu estudo, identificamos uma acentuada elevação dos coeficientes para causas externas ou violência na cidade do Rio de Janeiro em $1980(120,6)$ e em $1991(185,1)$. Já os valores dos coeficientes, por causas externas e violência, no município de São Paulo, foram 92,3 em 1980 e, em $1990,170,7$ por 100.000 habitantes e para ambos os sexos.

Um outro dado importante para esta discussão, além dos índices preocupantes, é a comprovação de que o trauma, quando não é fatal, transforma a vítima em um cliente grave que requer cuidados especializados com custos elevados. A recuperação deste cliente, quando ocorre, é lenta e às vezes deixa seqüelas incapacitantes que comprometem a qualidade de vida da pessoa, de sua família e, em particular, da sociedade em geral. Com base nesta afirmativa, o cuidado com estes clientes nos abre um mundo de opções para a assistência. São inúmeros os avanços tecnológicos, as possibilidades para a qualificação profissional necessários aos enfermeiros que cuidam do cliente com TCE, além da diversificação de guias de reabilitação e assim por diante. No entanto, numa visão mais abrangente, nós consideramos o cliente como o resultado de processos biológicos, sociais e espirituais e quaisquer que sejam os avanços científicos que venham a implementar à assistência, se não estiverem pautados no cliente e em suas necessidades, terá sua validade comprometida.

$\mathrm{O}$ cliente portador de TCE não é um doente crônico. A circunstância que o leva ao leito de um hospital, por ser súbita, o impossibilita de conduzir sua vida 
no ritmo normal. Os clientes com TCE são pais, filhos(as), esposos(as), amigos(as), namorados(as), enfim gente comum que independente de classe social, cor, idade e sexo; dão entrada nas Emergências dos grandes hospitais, desestruturando de uma hora para outra suas famílias e/ou círculo de amizade onde estão inseridos.

A família é considerada a célula básica da formação da sociedade. Ela é a instituição social que influencia tão fortemente um individuo que poderá determinar o sucesso ou o fracasso da vida deste (Friedman, 1992). É necessário considerar o contexto social, comportamental e hábitos nos quais o cliente está inserido.

Como célula básica da sociedade, a família influencia e é influenciada por forças externas (comunidade e um grande número de sistemas sociais) à sua volta. Muitos sociólogos acreditam que a influência da sociedade sobre a família seja grande, porém a familia também influencia a sociedade numa escala ménor. Embora possam existir inúmeros conceitos para esta instituição social, o que se adapta melhor ao nosso estudo é o que a define como um grupo de pessoas com laços através do casamento, sangue ou adoção. No entanto, outras definições podem nos dar um leque maior de opções, principalmente onde fossem incluidos grupos de lésbicas, gays, crianças, casais que coabitam juntos sem os laços do casamento, duas famílias que vivem em uma mesma casa, etc...

Em nosso estudo, o cliente com TCE, o familiar e/ou pessoa significativa formam um binômio e este não deve ser repartido. Mesmo que desconsiderássemos a crise familiar, ainda assim a família estaria presente, ao menos na qualidade de informante. Isto porque todos os membros do sistema familiar ou do sistema de pessoas significativas para o cliente são psicológica e comportamentalmente unidos uns aos outros, e estas conexões se desenvolveram por toda a extensão da vida deles. Qualquer mudança dentro de um elemento do sistema produz uma mudança em todo o sistema. É falho considerar a família como parte integrante da vida do cliente e instituir tratamento apenas para ele, sem abordar aquele grupo no qual está inserido (Testani-Dufour; Chappel-Aiken; Gueldner, 1994).

No contexto familiar, costuma-se dizer que a dor de um é a dor de todos. A participação e o suporte da família no momento em que toma conhecimento do fato é desejável para o sucesso do processo de reabilitação. Desde o momento em que a notícia é dada: "seu familiar sofreu um traumatismo craniano", a crise se estabelece e as vidas são mudadas desde então. Quando algo brusco ocorre no meio familiar e o perigo de vida é iminente, é comum buscar-se métodos para controlar a situação rapidamente e, portanto, sem reflexão e sem resolutividade. Um bom exemplo é apegar-se à esperança de que o cliente sobreviverá, independente da gravidade de seu estado, sem reconhecer que a morte poderá acontecer mais cedo ou mais tarde. Familiares precisam manter-se informados das verdadeiras condições do cliente até mesmo para chorarem, compartilharem 
sentimentos, falarem sobre suas expectativas ou sentarem-se em silêncio. Precisam de tempo para cuidar de negócios intermináveis, e para dizer adeus ao familiar, antes ou depois dos respiradores e órgãos tecidos serem removidos (Cooligan, 1994). Muitas vezes, o dia a dia na Emergência impede-nos de atentar para os sentimentos que estes familiares estão vivenciando por ocasião do TCE de um membro do grupo. Portanto, existem razões que justificam a assistência aos familiares dos clientes com TCE, que são descritos por Friedman (1992).

- Numa família unida, qualquer disfunção em um dos membros (doença, ferimentos, separação) se reflete nos demais;

- Existe uma forte interrelação entre a família e a saúde de seus membros, pois a necessidade de promover o bem-estar para cada um deles torna-se importante para todos;

- Promover o autocuidado, educação para saúde e aconselhamento familiar são fundamentais para implementar e estimular o bem-estar de seus membros, principalmente do cliente com TCE, que precisará da família em seu longo processo de reabilitação;

- A presença de um problema de saúde em um dos membros pode ser fundamental para descobrir doenças ou fatores de risco nos demais;

- O profissional só pode alcançar um claro entendimento de seu cliente e de sua fisiologia quando o vê no contexto familiar;

- Tanto a família pode ser um suporte vital para o cliente com TCE quanto suas propostas do problema em questão podem ser avaliadas e incorporadas aos planos de tratamento de enfermagem.

Já os diagnósticos de enfermagem propiciam um mecanismo útil para estruturar o conhecimento de enfermagem e para definir um único papel para os profissionais. Expressam nosso julgamento clínico sobre as respostas destes à doença, enfim, sobre os fenômenos que requerem cuidados pela enfermeira, uma vez que o diagnóstico de enfermagem ajuda a definir o âmbito e a ação profissional.

Nesse estudo, adotamos o referencial das Necessidades Humanas Básicas Afetadas (NHBA) de Wanda Horta e o seu modelo de Processo de Enfermagem.

Neste trabalho, entretanto, utilizaremos a Taxonomia (Nóbrega; Garcia, 1992) e a definição da Nanda (NORTH AMERICAN NURSING DIAGNOSIS ASSOCIATION) para Diagnóstico de Enfermagem (DE).

\footnotetext{
Diagnóstica de enfermagem é um julgamento clinico sobre as respostas do individuo, da familia, ou da comunidade para as processos de saude vitais.
} 
Os diagnósticas de enfermagem fornecem a base para a seleção das intevvencoöes de enfermagem para atingir resultados pelos quais a enfermeira é responsável." (Carpenito, 1999)

Este trabalho baseia-se nos princípios científicos que norteiam a sistematização da assistência de enfermagem, na tentativa de dar autonomia e independência à enfermeira.

Os princípios desta Teoria são deduzidos por Horta (1979):

- A enfermagem respeita e mantém a unicidade, autenticidade e a individualidade do ser humano;

- A enfermagem é prestada ao ser humano e não à sua doença ou desequilíbrio;

- Todo o cuidado de enfermagem é preventivo, curativo e de reabilitação;

- A reabilitação reconhece o ser humano como elemento participante ativo do seu autocuidado.

Diante do que foi discutido, o estudo tem os seguintes objetivos:

- Identificar os diagnósticos de enfermagem mais freqüentes no cliente portador de TCE, familiar e/ou pessoa significativa, no Setor de Trauma e/ou demais dependências do HUAP em que não fique caracterizada a internação;

- Nomear os diagnósticos de enfermagem segundo a Taxonomia I da NANDA classificando-os conforme a Teoria das Necessidades Humanas Básicas Afetadas de Wanda Horta.

\section{METODOLOGIA}

$\mathrm{Na}$ oportunidade da testagem do instrumento de coleta de dados e tendo em vista o nosso interesse em identificar diagnósticos de enfermagem no cliente portador de TCE, familiar e/ou pessoa significativa, visamos aplicar os instrumentos de coleta de dados para sua testagem e a do método a ser utilizado no estudo. Trata-se de um estudo descritivo, em que utilizamos o método qualitativo.

O campo de realização foi o Hospital Universitário Antônio Pedro da Universidade Federal Fluminense, na cidade de Niterói-RJ.

O estudo descreve o trauma de um cliente com idade superior a 18 anos e seu primo, também com idade acima dos 18 anos, que o acompanhava no 
momento em que foi atropelado e que lhe prestou socorro. A coleta de dados foi realizada de forma diferenciada, pois foram utilizados dois instrumentos:

\section{A. Descrição do Cliente portador de TCE}

- Cliente adulto submetido a exame físico e observação, além da consulta ao Boletim de Emergência e/ou Ficha Única. A abordagem ao cliente foi feita através do Histórico que serviu de base para a coleta de dados. O cliente foi submetido à Escala de Coma de Glasgow durante o exame físico, para testar principalmente niveis de consciência para submetê-lo a entrevista ou não. $O$ instrumento de coleta de dados constou de duas partes: a entrevista e o exame físico que reforçou a necessidade de coletar dados através do informante familiar, já que o cliente encontrava-se inconsciente. As informações referentes ao exame físico, além de terem sido registradas no Boletim de Emergência e/ou Ficha Única.

\section{B. Familiar e/ou Pessoa Significativa do Cliente}

- Cliente adulto submetido a entrevista e observação. A observação foi feita durante a entrevista, de forma que houve condição de detectar estados de tensão e estresse.

Os dados foram coletados em um único dia, durante o plantão de sexta-feita à noite, dia em que o número de acidentes costuma ser maior. A interpretação dos resultados culminou com a formulação de vários diagnósticos de enfermagem que foram validados por meio da Taxonomia I da NANDA e segundo os critérios preconizados por Cruz (1993). Para tanto foram utilízados os instrumentos auxiliares do procedimento do diagnóstico (Cruz, 1993). Neste instrumento, o julgamento clínico é definido operacionalmente como habilidade para:

- Levantar dados significativos;

- Correlacionar dados entre si, agrupando-os;

- Nomear os grupamentos conforme a Taxonomia I (Cruz, 1993);

- Identificar os fatores relacionados ou de risco;

- Classificar o diagnóstico em atual, potencial ou possível; e

- Validar o diagnóstico pela Taxonomia I.

$O$ instrumento é dividido em três partes:

Parte A: Dados significativos - Estes dados são listados conforme o grau de importância para o enfermeiro; 
Parte B: Grupamento dos Dados Significativos - Os dados são grupados pelo enfermeiro para que denotem um padrão ou uma resposta comportamental; e

Parte C: Nomeação - Os grupos constantes na parte B são nomeados pelo enfermeiro que especifica o fator relacionado, relacionando os dados significativos que fundamentam tanto o diagnóstico, quanto o fator relacionado, e caracteriza a sua tipologia.

\section{QUADRO 1: ESCALA DE MENSURAÇÃO DO PROCEDIMENTO DIAGNÓSTICO}

(1) Levantamento de dados significativos

0: não levanta dados

1: levanta dados, mas nenhum tem relação com as características definidoras descritas na Taxonomia I

2: levanta dados, sendo que pelo menos um é compativel com as características definidoras descritas na Taxonomia I

(2) Relação dos dados, formação de grupamentos

0: não faz grupamentos ou agrupa um único dado

1: agrupa menos de três dados para diagnósticos atuais ou potenciais; menos de dois dados para diagnósticos possiveis

2: agrupa três ou mais dados para diagnósticos possiveis

(3) Nomeação

0: não nomeia o grupamento ou nomeia inadequadamente

1: nomeia, não utilizando a Taxonomia I como referência

2: nomeia, utilizando a Taxononia I

(4) Identificação dos fatores relacionados ou de risco

0: não identifica fatores relacionados ou de risco

1: identifica fatores relacionados sem dados que os fundamente

2: identifica fatores relacionados fundamentando-os com pelo menos um dado

(5) Classificação em atual, potencial ou possivel

0: não classifica o diagnóstico

1: classifica, porém sem observar os critérios listados para o item (2)

2: classifica atendendo aos critérios

0 a 2 = completamente errado $/$ completamente certo 


\section{METODOLOGIA}

O estudo de caso clínico é correspondente ao binômio cliente com TCE/ familiar e/ou pessoa significativa a este cliente.

\section{* Estudo de Caso do Cliente com TCE - BE 033469}

E.J.A., 31 anos, masculino, casado, negro, pedreiro, deu entrada no setor de traumatologia no dia 09.06.95, por volta das $20: 15 \mathrm{~h}$, procedente da via pública, vítima de TCE causado por atropelamento em frente à praça do pedágio da ponte Rio-Niterói, socorrido pela ambulância do Corpo de Bombeiros. Ao dar entrada no setor encontrava-se inconsciente com Glasgow 3, FR = $30 \mathrm{mov} / \mathrm{min}$, expansão assimétrica da caixa torácica, taquipnéia, eliminando secreções sanguinolentas pelas fossas nasais, F.C. 100 bat $/ \mathrm{min}$., pulso rítmico e cheio, P.A. $=150 \times 100 \mathrm{mmHg}$, verificada no MSE com o cliente em decúbito dorsal, sudoreico, $\mathrm{T}=35,7^{\circ} \mathrm{C}$ axilar, alcoolizado, escoriações, edema em MIE e laceração do tecido em região frontal esquerda e cotovelo direito. Após a administração de 6 ampolas de glicose hipertônica a 50\% e $1000 \mathrm{ml}$ de ringer lactato em veia periférica puncionada em membro superior direito, passou a apresentar Glasgow 14. Ao ser encaminhado ao Setor de RX, já fazia uso de sonda vesical de demora, sonda nasogástrica em sinfonagem e hidratação venosa em MSD. Com níveis de consciência mais elevados, torpor com períodos de inconsciência, começou a chamar por seu compadre. Contido no leito, ansioso e agitado tentava soltar-se. Sua expressão fisionômica era transtornada, angustiado, reclamava de dor na cabeça e no MIE, principalmente quando era manuseado. Após a tomografia e o RX do crânio e MIE, detectou-se hematoma craniano epidural laminar esquerdo, fratura temporal esquerda e fratura femural, tíbia e sínfise pubiana. Horas mais tarde já conseguia prestar mais informações. Seu estado nutricional era bom, peso em torno de $75 \mathrm{~kg}$, altura por volta de 1,74 $\mathrm{cm}$. Informou alimentar-se bem com frutas, saladas, peixe, arroz e feijão, isto em grandes quantidades. Suas refeições são distribuídas em 4 horários diferentes (7 horas, café da manhã; almoço por volta das 12 horas; lanche às 15 horas e jantar às 21 horas). Relatou beber muita água, refrigerante, cerveja e traçados (cachaça + mel). Disse que bebe todos os dias pós o trabalho e durante 0 almoço. Relatou que normalmente elimina fezes consistentes. Evacuou 1 vez pastoso em grande quantidade. Diurese estava presente em grande quantidade $( \pm 800 \mathrm{ml}$ ), porém perdeu durante o transporte. Informou não ter problemas para adormecer e que dorme em média 7 horas por noite e 30 minutos após o almoço. Sua atividade física restringe-se ao trabalho pesado. Sua musculatura é rija e a força mantém-se presente. Sua higiene limita-se ao banho de aspersão duas vezes ao dia, porém disse não escovar os dentes e apresenta sérios problemas com raizes inclusas em péssimo estado de conservação; cabelos limpos e tratados. Relatou que reside em dois cômodos com a família e sem 
barreiras arquitetônicas; 5 pessoas coabitam juntas. A residência possui luz elétrica, água encanada, rede de esgoto e o lixo não é coletado e sim queimado. Disse ser tabagista (duas carteiras por dia) e bebe grandes quantidades de cachaça. Pouco soube informar sobre sua vacinação, apenas lembra de ter tomado várias. Mantém relacionamento sexual satisfatório com a esposa e acredita que seu acidente irá intervir no seu desempenho. Informou que não se sente bem e que vai ter que afastar-se do trabalho em conseqüência da fratura na cabeça e na perna esquerda. Relatou que é católico, porém não praticante e naquele momento achava desnecessária a presença de um padre ou qualquer outro religioso de sua igreja.

\section{* Estudo de Caso de Familiar/Pessoa Significativa do Cliente com TCE}

W.V., 53 anos, masculino, branco, casado, bombeiro hidráulico, primo da esposa do cliente e compadre deste, na ocasião do acidente encontrava-se nervoso e chorava muito. Informou que não costumava ir ao médico ou fazer exames periódicos. Relatou sofrer dos nervos e por isso estava encostado. Trabalhou durante 20 anos antes de sofrer a primeira crise nervosa. Vez por outra, quando encontra-se sob forte tensão, apresenta tremores e perde a noção do lugar onde está. Faz uso de Gardenal e Diazepan. É fumante de longa data e costuma não tomar os medicamentos quando vai beber. Não possui doenças hereditárias na família, não se submete a exercícios e costuma dormir bem. Seu relacionamento sexual informou ser satisfatório com sua esposa. Não acredita que a doença de seu amigo poderá interferir no seu desempenho sexual. Suas tensões são aliviadas através do uso dos medicamentos controlados. Disse que costuma ficar ansioso, agitado e amedrontado diante de fortes estados emocionais. $\mathrm{Na}$ ocasião, demonstrou um forte sentimento de culpa em função do atropelamento que assistiu. Relatou que estava com a vítima na hora do acidente e nada pôde fazer para impedi-lo de atravessar a pista. Disse sentir pelo amigo uma grande responsabilidade de como se fosse seu filho. $\mathrm{Na}$ ocasião não achou necessária a presença de alguém para lhe dar conforto espiritual, embora dissesse ser católico. Após a entrevista mostrava-se mais calmo e foi convidado a participar dos exames do amigo para confortá-lo.

A partir da coleta de dados e do estudo de caso, agrupamos os dados significativos de acordo com as necessidades psicobiológicas, psicossociais e psicoespirituais. Num segundo momento, os dados foram novamente reagrupados obedecendo as NHBA. E finalmente, em um terceiro momento, os diagnósticos foram avaliados conforme a escala de mensuração do procedimento diagnóstico e validados pela literatura.

\section{RESULTADOS}

Os resultados que apresentamos nos levaram à identificação e nomeação de diagnósticos de enfermagem indicando a seriedade dos problemas enfrentados pelos clientes com TCE, vítimas de acidentes de trânsito, bem como do familiar 
e/ou pessoa significativa que costuma apresentar várias alterações em função do acontecido com seu parente e/ou amigo.

Foram encontrados os seguintes diagnósticos de enfermagem para o cliente com TCE.

\section{Eliminação Tráqueo-Brônquica Ineficaz (1.5.1.2)}

É definido como o estado no qual o indivíduo é incapaz de eliminar secreções ou obstruções do tracto respiratório, para mantê-lo livre (Nóbrega; Garcia, 1992).

O diagnóstico em questão surgiu em função da perda da consciência. Esta perda momentânea, nos casos mais leves, não tem maiores conseqüências, porém, nos casos mais graves, rapidamente faz o cliente evoluir para o estado de coma.

Sheehy; Jimmerson (1994) apontam, então, a perda da consciência, a síncope, o trauma em si, secreções no tracto respiratório, náusea acompanhada de vômitos e outros déficits neurológicos como predisponentes para o surgimento deste diagnóstico. Foram levantados 12 dados significativos para este diagnóstico.

\section{QUADRO 2 - DADOS SIGNIFICATIVOS ENCONTRADOS PARA A IDENTIFICAÇÃO DO DIAGNÓSTICO DE ENFERMAGEM - ELIMINAÇÃO TRÁQUEO- BRÓNQUICA INEFICAZ}

\section{Dados Significativos}

- Perda momentânea da consciência;

- Glasgow < 15;

- Presença de secreção sanguinolenta no tracto respiratório acompanhada de tosse;

- Taquipnéia;

- Tabagismo;

- Respiração irregular;

- Expansão assimétrica da caixa torácica;

- Alcoolismo;

- Agitação;

- Estado semi-comatoso;

- Trauma facial;

- Sudorese.

Das 6 caracteristicas definidoras apresentadas por Nóbrega; Garcia (1992), conseguimos correlacionar 4 delas às nossas.

Este diagnóstico de enfermagem demanda uma maior atenção no sentido de manter o cliente em observação constante e interferir na desobstrução do trato 
respiratório, evitando que este venha a falecer em função de obstrução das vias aéreas superiores causadas por acúmulo de secreções, vômitos, próteses, etc.

Sparks; Taylor (1995), ao descreverem a importância deste diagnóstico, o apresentam ligado ao Trauma (TCE e ao Traumatismo Raquimedular). Ligado ao TCE, este diagnóstico relaciona-se ao "status" neurológico incluindo niveis de consciência e orientação.

Com a alta incidência, o diagnóstico Eliminação, Traqueobrônquica Ineficaz possui paralelo na literatura, mais especificamente nos trabalhos de Capuano (1991), Gift (1991) e Smeltzer (1992) que também levantaram o mesmo diagnóstico em clientes traumatizados.

\section{Potencial para Aspiração (1.6.1.4)}

É o estado no qual o individuo apresenta o risco de entrada de secreções gastrointestinais, secreções orofaringeas, sólidos ou líquidos na via tráqueobrônquica (Nóbrega; Garcia, 1992).

Para o diagnóstico Potencial para Aspiração identificamos 7 dados significativos que conseguimos correlacionar com 3 caracteristicas definidoras relatadas por Nóbrega; Carcia (1992).

Acrescentamos que a diminuição dos niveis de consciência foi o fator de risco preponderante para o aparecimento deste diagnóstico.

Ainda quanto ao diagnóstico de enfermagem Potencial para Aspiração, apresentaremos no quadro a seguir os dados significativos identificados para este diagnóstico.

\section{QUADRO 3 - DADOS SIGNIFICATIVOS ENCONTRADOS PARA A IDENTIFICAÇÃO DO DIAGNÓSTICO DE ENFERMAGEM - POTENCIAL PARA ASPIRAÇÃO}

\section{Dados Significativos}

- Glasgow < 15;

- Secreção sanguinolenta

no tracto respiratório acompanhada de tosse;

- Taquipnéia;

- Alcoolismo;

- Torpor com período de agitação;

- Uso de sonda nasogástrica;

- Trauma facial

Grant; Murray; Bergeron (1994) apontam para os cuidados emergenciais que devem ser dados aos clientes portadores de TCE e dentre eles a 
manutenção das vias aéreas desobstruidas para que o cliente possa respirar normalmente.

Determinadas ações de enfermagem, quando não tomadas, podem favorecer ou agravar o alto risco do cliente para aspiração que, por sua vez, é predisponente para complicações e infecções pulmonares sérias.

O diagnóstico Potencial para Aspiração foi encontrado nos trabalhos de Dalri (1993); Logan; Jenny (1990) e Logan; Jenny (1991), ainda que numa amostra diferenciada do TCE.

\section{Mobilidade Física Prejudicada (6.1.1.1)}

Estado no qual o indivíduo experimenta uma limitação na habilidade para movimentos físicos independentes (Nóbrega; Garcia, 1992).

O surgimento deste diagnóstico deu-se em função do cliente apresentar fraturas que comprometiam a sua locomoção, além de outros dados ligados a níveis de consciência.

A seguir apresentaremos os dados significativos levantados para este diagnóstico.

\section{QUADRO 4 - DADOS SIGNIFICATIVOS ENCONTRADOS PARA A IDENTIFICAÇÃO DO DIAGNÓSTICO DE ENFERMAGEM - MOBILIDADE FÍSICA PREJUDICADA}

\section{Dados Significativos}

- Acamado;

- Fraturas múltiplas em membro inferior esquerdo (tíbia, fêmur e sínfise pubiana);

- Edema em membro inferior esquerdo;

- Agitação;

- Contido no leito;

- Glasgow > 15.

O Quadro 4 nos mostra que foram encontrados 6 dados significativos que conseguimos correlacionar com 4 características definidoras levantadas por Nóbrega; Carcia (1992).

Encontramos o levantamento deste diagnóstico no estudo de Levin et al (1989) como também no estudo de Quellet; Rush (1990)

Encontramos também este diagnóstico no estudo de Andrade; Cruz (1994) ligado à falta de memória visual, de confiança para mover-se no espaço físico, à 
perda de independência e à dependência para locomoção, como fatores relacionados à perda de mobilidade.

Os resultados apresentados nos levam a crer que os clientes com TCE correm o risco de apresentarem este diagnóstico, determinado pelo próprio conjunto de suas condições físicas, pois ele é um politraumatizado.

\section{Potencial para Infecção}

Estado no qual o individuo está com risco aumentado para ser invadido por organismos patogênicos (Nóbrega; Garcia, 1992).

Muitos clientes que sobrevivem a traumatismos graves podem, no entanto, vir a falecer em função de septicemia, a segunda causa de morte em clientes pós-trauma. Os mecanismos de defesa estão comprometidos por lesões na pele, nos ossos e na integridade dos órgãos, dando aos organismos oportunidades de causar infecção e especialmente durante os cuidados clínicos através de procedimentos invasivos. Muitos dos nossos clientes com TCE, além das lesões externas, tiveram lesões internas, principalmente fraturas complicadas, processos hemorrágicos causados pelo TCE, que os levaram a complicações respiratórias, sendo necessária a entubação como outros procedimentos invasivos.

Apresentaremos no quadro a seguir os dados significativos levantados para este diagnóstico.

\section{QUADRO 5 - DADOS SIGNIFICATIVOS ENCONTRADOS PARA A IDENTIFICAÇÃO DO DIAGNÓSTICO DE ENFERMAGEM - POTENCIAL PARA INFECÇÃO}

\section{Dados Significativos}

- Higiene oral precária;

- Focos de infecção, cáries, raízes dos dentes à mostra;

- Condições precárias de moradia;

- Desconhecimento sobre imunização;

- Laceração de tecido em região frontal esquerda e cotovelo direito;

- Uso de sonda nasogástrica;

- Uso de sonda vesical;

- Punção venosa em membro superior direito;

- Reside em dois cômodos, com 4 pessoas;

- Lixo não coletado, queimado.

Conseguimos levantar 10 dados significativos, agrupar e correlacionar com 6 características das 11 apontadas por Nóbrega; Garcia (1992).

A estrutura nos aponta o levantamento do diagnóstico Potencial para Infeção nos estudos de Lenagnan (1992), quando a autora aborda clientes 
politraumatizados, em Dalri (1991) sobre clientes queimados e, finalmente, nos estudos de Santos; Almeida; Silva (1995), quando os autores, através de um levantamento bibliográfico, apontaram a existência deste diagnóstico em vários autores e demonstraram a sua importância na assistência de enfermagem.

Carpenito (1992) relata que a resistência à infecção depende da resposta auto-imune, da virulência do micro-organismo e da quantidade do agente agressor e que alguns fatores, no entanto, podem apresentar-se como barreira e, dentre eles, incluem-se barreiras anatômicas, terapias, desenvolvimento de barreiras hereditárias, fatores hormonais, idade, nutrição, febre, presença de secreção que pode diminuir a proliferação bacteriana ou ter ação bactericida, endotoxinas combatendo outros microorganismos, ativação de leucócitos devido ao processo inflamatório e fagocitose.

Precisamente, na assistência ao cliente com TCE e diante até de algumas barreiras que costumam evitar que todos os clientes sucumbam aos processos infecciosos, tanto a autora como Lenaghan (1992) apontam intervenções voltadas para a higiene, como o simples lavar de mãos antes e depois de cuidar dos doentes como suficiente para controlar o processo de infecção, como também cuidados com cateteres, feridas e demais medidas de controle à infecção.

\section{INTEGRIDADE TISSULAR PREJUDICADA (1.6.2.1)}

Estado no qual o indivíduo apresenta lesão em mucosas, córnea, tecido cutâneo ou subcutâneo (Nóbrega; Carcia, 1992).

As lesões provocadas durante 0 atropelamento foram as mais variadas. Encontramos lesões do tipo escoriativa, laceraçōes, cortes profundos, feridas abertas, perda de pelo, fraturas abertas ou fechadas, feridas corto contusas, hematomas dentre outras.

No quadro a seguir apresentaremos os dados significativos identificados para o diagnóstico.

\section{QUADRO 5 - DADOS SIGNIFICATIVOS ENCONTRADOS PARA A IDENTIFICAÇÃO DO DIAGNÓSTICO DE ENFERMAGEM - INTEGRIDADE TISSULAR PREJUDICADA}

\section{Dados Significativos}

- Escoriações;

- Hematoma em tecido cerebral;

- Edema em região frontal esquerda;

- Fraturas: crânio, tíbia, fêmur e sínfise pubiana;

- Laceração de tecido em região frontal e cotovelo direito 
Para este diagnóstico correlacionamos a única caracteristica definidora encontrada em Nóbrega; Garcia (1992) às 5 nossas.

Embora a característica definidora, Tecido Lesado ou Destruído tenha agrupado tanto dados significativos encontrados no cliente com TCE, dos estudos que levantamos até então, apenas Hudson-Goodsman; Girard; Jones (1990) apontaram o diagnóstico associado a destruição de tecidos por ferimentos mais profundos; os demais trabalhos relacionavam-se a úlceras de decúbito, tais como: Kranski (1992) e Maklebust, Magman (1992). Talvez Gordon (1995) tenha a resposta para os escassos estudos encontrados. Em recente trabalho sobre a freqüência do aparecimento dos diagnósticos no cuidado aos clientes graves, vamos encontrar a percentagem de $58 \%$ para o diagnóstico Integridade Tissular Prejudicada em contrapartida aos 92\% para o Potencial para Infecção. Com tantas lesões importantes, muitos clientes com TCE tornam-se crônicos em função de serem politraumatizados e conseqüentemente sujeitos a adquirirem infeção devido à imobilidade e até mesmo à contaminação no próprio ambiente hospitalar. Seria essa a explicação para a freqüência tão elevada para o diagnóstico Potencial para Infeç̧ão em detrimento dos demais, apenas supomos.

\section{ANSIEDADE (9.3.1)}

Estado subjetivo no qual 0 individuo experimenta um sentimento de incômodo e inquietação, cuja fonte é, freqüentemente, inespecifica ou desconhecida por ele (Nóbrega; Carcia, 1992).

Um dos diagnósticos mais comuns entre os clientes com TCE, a ansiedade gerada pelo trauma, se não tratada, leva ao aparecimento de sintomatologias gástricas que deverão ser combatidas.

A ansiedade pós-trauma é uma resposta do mecanismo simpáticoadrenérgico. O cliente com TCE pode rapidamente desenvolver um quadro de gastrite ou úlcera gástrica pela estimulação do hipotálamo, aumentando o seu metabolismo devido às fortes descargas adrenérgicas, a que vem se submetendo até então, desde o momento do acidente.

Além do aparecimento das sintomatologias gástricas, acrescentamos os processos de hiperglicemia, déficits nutricionais e infecção pós-traumática.

No quadro a seguir apresentaremos alguns dados significativos encontrados para a identificação do diagnóstico. 


\section{QUADRO 7 - DADOS SIGNIFICATIVOS ENCONTRADOS PARA A IDENTIFICAÇÃO DO DIAGNÓSTICO DE ENFERMAGEM - ANSIEDADE}

\section{Dados Significativos}

- Ansiedade;

- Expressão fisionômica transtornada;

- Dor na cabeça e no membro inferior esquerdo quando manuseado;

- Contenção no leito;

- Respiração irregular (30 mov/min);

- Taquipnéia;

- Angústia;

- Agitação psicomotora;

- Sudorese.

Conseguimos correlacionar 8 dados significativos e 3 características definidoras encontradas em Nóbrega; Garcia (1992).

Encontramos o diagnóstico Ansiedade nos trabalhos de Taylor-Loughran et al (1989), onde as autoras validam os diagnósticos Ansiedade e Medo em clientes hospitalizados. No estudo de Cruz (1993), ele também foi identificado em 3 clientes portadores de hipertensão arterial essencial, como também no estudo de Dalri (1992), em doze clientes queimados, conseguindo a autora levantar 26 caracteristicas definidoras, entre subjetivas e objetivas.

A ansiedade não surge sem motivo aparente. Eisenman; Cohen (1995) apontam a admissão hospitalar e os procedimentos cirúrgicos como fatos que levam os clientes a apresentarem altos niveis de estresse.

Segundo Engler; Engler (1995), o organismo, antes de apresentar o quadro de estresse, passa por três estágios: o estágio de alarme, o estágio de resistência e o estágio de exaustão (o estresse persiste e não consegue ser debelado). Concluimos, então, que os dados significativos que permearam o diagnóstico Ansiedade nos mostram que o cliente com TCE manteve-se por muito tempo sob pressão de risco cirúrgico devido às múltiplas lesões, às luzes intermitentes em seus olhos 24 horas por dia, ao barulho da movimentação tão característica do próprio setor e ao barulho provocado por outros clientes com patologias diferenciadas da sua, entre outros.

Para nós, a presença de um familiar e/ou pessoa significativa com baixos niveis de estresse muito contribui para que o cliente com TCE consiga não debelar totalmente $\circ$ quadro, pois $\circ$ estresse faz parte de nossas vidas e não pode ser evitado, porém relaxar bastante.

Foi encontrado o seguinte diagnóstico para o Familiar do cliente com TCE. 


\section{ANSIEDADE (9.3.1)}

Estado subjetivo no qual 0 indivíduo experimenta um sentimento de incômodo e inquietação, cuja fonte é, freqüentemente, inespecifica ou desconhecida por ele (Nóbrega; Garcia, 1992).

$O$ diagnóstico Ansiedade repetiu-se no familiar do cliente com TCE, isto porque a familia e/ou pessoa significativa ao cliente com TCE enfrenta, diante da surpresa de um TCE por acidente de trânsito, uma crise situacional, desorganização temporária da familia, e a processos de inadequação, entre outros.

No quadro abaixo apresentaremos os dados significativos encontrados no familiar do cliente com TCE.

\section{QUADRO 7 - DADOS SIGNIFICATIVOS ENCONTRADOS PARA A IDENTIFICAÇÃO DO DIAGNÓSTICO DE ENFERMAGEM - ANSIEDADE}

\section{Dados Significativos}

- Ansiedade;

- Medo;

- Agitação;

- Sentimento de culpa;

- Assume grande responsabilidade pelo cliente com TCE;

- Assistiu ao atropelamento;

- Tremores generalizados;

- Perde a noção onde está quando fica nervoso;

- Crise nervosa acompanhada de choro.

Foram levantados 9 dados significativos para o diagnóstico Ansiedade. Conseguimos correlacioná-los a 3 características definidoras subjetivas e a características definidoras objetivas encontradas em Nóbrega; Carcia (1992). Este diagnóstico foi encontrado em um único familiar, no caso primo do cliente com TCE. Encontramos o mesmo diagnóstico no estudo de Testani-Dufour; Chappel-Aiken; Gueldner (1992), quando as autoras relatam uma experiência familiar com clientes vitimas de TCE. 


\section{CONSIDERAÇÕES FINAIS}

Com base no estudo de caso, não somos pretensiosos o suficiente para afirmarmos que solucionamos todos os problemas do cliente com TCE e do familiar deste. No entanto, reconhecemos que o momento terapêutico, resultado do contato com os dois clientes em função do levantamento dos diagnósticos, resultou em melhora do quadro de ambos. Além disso, a necessidade de conhecermos em parte o perfil dos clientes com TCE e de seu familiar, com base nos diagnósticos de enfermagem, nos ajudou em muito a elaborar o arcabouço da nossa dissertação de mestrado.

Configuramos certa dificuldade, a princípio, em elaborar os diagnósticos de enfermagem em virtude da nossa formação biomédica. No entanto, o uso dos instrumentos auxiliares do procedimento diagnóstico bem como da escala de mensuração do procedimento diagnóstico facilitaram o levantamento e validação dos mesmos.

Tendo em vista os objetivos propostos, chegamos às seguintes conclusões:

1. Identificamos 6 diagnósticos de enfermagem para os clientes portadores de TCE e 1 para o familiar deste, utilizando-se a Taxonomia I da NANDA.

Embora tenhamos levantado estes 7 diagnósticos em apenas um estudo de caso e conseguido validá-los pela literatura e com o escore máximo de 10 pontos, acreditamos que um painel de juizes seria o ideal para validá-los.

2. Nomeamos os diagnósticos de enfermagem com base no Referencial Teórico de Wanda Horta.

A abordagem holistica do cliente com TCE e do familiar confirma a necessidade de enxergá-los como seres psicobiológicos, psicossociais e psicoespirituais que necessitam de nossa assistência para, senão sanar, minimizar os fenômenos de que são vítimas.

Acreditamos que os caminhos que foram abertos através dos diagnósticos de enfermagem servirão como contribuição ao conhecimento dos aspectos que emergem dos clientes com TCE e de seus familiares.

ABSTRACT: This paper presents a case study related to a client with head injury and his relatives and/or significant people seeking Nursing Diagnosis stated according to Taxonomy of NANDA (North American Nursing Diagnosis Association), were classified based on Wanda Horta's theory of unmet Basic Human Needs. Two instruments of data collection have been applied where it has been revealed 6 nursing diagnosis for the client and 1 nursing diagnosis for the relative.

KEYWORDS: Head injuries - Family - Significant people - Nursing diagnosis. 


\section{REFERÊNCIAS BIBLIOGRÁFICAS}

1. ANDRADE SILVA, R. C. R; CRUZ, I.C.F. da. Diagnóstico de Enfermagem a partir da Taxonomia da NANDA em Clientes Deficientes Visuais. $R$. Enferm. UERJ, v. 2, n. 1, p. 57-69, 1994.

2. CAPUANO, T. et al. Respiratory Nursing diagnoses: Nurses' ability to select their defining characteristics. In: CAROLL-JOHHNSON, $R$. Classification of Nursing Diagnosis: Proceedings of the ninth Conference. Philadelphia, J. B. Lippincott, 1991.

3. CARPENITO, L. J. Nursing Diagnosis Application to Clinical Practice. 5. ed. Philadelphia, J. B. Lippincot, 1993, p. 97-869: Manual of Nursing Diagnosis.

4. CRUZ, D. de A.L.M. da. Alterações do padrão respiratório: Avaliação e intervenções de enfermagem. Acta. Paul. Enf. v. 8, n. 2, p. 15-20, 1994.

5. CRUZ, I. C. F. da. Diagnósticos de Enfermagem Estratégias para sua Formulação e Validação. São Paulo, 1993. 106 p. Tese (Doutorado) Escola de Enfermagem, Universidade de São Paulo.

6. EISENMAN, A.; COHEN, B. Music Therapy for patients undergoing regional anesthesia. AORNJJOURNAL v. 62, n. 6, p. 947-50, 1995.

7. ENGLER, M. B.; ENGLER, M.M. Assessmente of the cardiovascular effects of stress. The Journal of Cardiovascular Nursing. v. 10, n. 1, p. 51-63, 1995.

8. FRIEDMAN, M. M. Family Nursing Theory and Practice. 3. ed. Connecticut, Appleton; Lange, 1992, cap. 2, p. 21-36: Family Nursing: Focus, Evolution and Godes.

9. GRANT, H. D.; MURRAY, R.H.JR.; BERGENSON, J.D. Injuries tothe Skull and Brain. In: Emergency care. 6 ed. New Jersey: Brady, 1994. cap. 12, p. 329-338.

10. HORTA, W. de A.; CASTELLANOS, B.E.P. (ed.) Processo de Enfermagem. São Paulo, E. PU, 1979. cap. 1, p. 3-27. Filosofia, teoria e ciência de enfermagem.

11. HUDSON-GOODMAN, P.; GIRARD, N.; JONES, M. B. Wound repair and the use of growth factors. Heart and Lung. v. 19, n. 9, p. 379-384, 1990.

12. KRAINSKI, M. M. Pressure ulcers and the elderly. Ostomy/Wound Management. v. 38, n. 5, p. 22-37, 1992.

13. LENAGHAN, N.A. After the Trauma...Managing its effects down to the last letter. Nursing. v. 22, n. 3, p. 44-8, 1992.

14. LEVIN, R.F. et al. Diagnostic content validity of nursing diagnosis. Image, $v$. 21, n. 1 , p. $40-44,1989$.

15. LOGAN, J.; JENNY, J. Deriving a new nursing diagnosis through qualitative research. Dysfunctional ventilatory weaning response. Nursing Diagnosis. v. 1, n. 1, p. 37-43, 1990. 
16. LOGAN, J.; JENNY, J. Interventions for the Nursing diagnosis dysfunctional ventilatory weaning response: A qualitative study. In: CARROLJOHNSON, R.M. (ed.) Classification of Nursing diagnosis: Proceedings of the Ninth Conference, Philadelphia: J.B. Lippincott, 1991.

17. MAKLEBUST, J.; MAGNAN, M. Approaches to patient and family education for pressure ulcer management. Decubitus. v. 5, n. 3, p. 43-47, 1992.

18. MINISTÉRIO DA SAÚDE. Secretaria Nacional de Ações Básicas de Saúde. Divisão Nacional de Epidemiologia. Estatísticas de Mortalidade Brasil, 1980. Brasília, Centro de Documentação do Ministério da Saúde, 1983. p. 354 (Série G: Estatísticas e Informação em Saúde, 3).

19. NÓBREGA, M.M.L. da; GARCIA, T.R. Uniformização da linguagem dos diagnósticos de Enfermagem da NANDA: Sistematização das propostas do II SNDE. João Pessoa, 1992.

20. QUELLET, L.; RUSH, K.A. Synthesis of selected literature on Mobility: A basis for studying Imipaired Mobility. Nursing Diagnosis, v. 3, n. 2, p. 72-90, 1992.

21. SANTOS, C.T.S. dos; ALMEIDA, D.C.; SILVA, M. dos. Potencial para Infecção: Diagnóstico e Prescrição de Enfermagem. In: I Simpósio Internacional sobre Diagnóstico de Enfermagem, São Paulo, 1995. Programa. São Paulo. Escola de Enfermagem da USP, Departamento Médico-Cirúrgico, 1995, p. 22 / Resumo.

22. SHEENY, S.B.; JIMMERSON, C.L. Manual of Clinical Trauma Care: The first hour. 2 ed. MISSOURI: Mosby, 1994. Cap. 19, p. 267-304: Head Trauma.

23. SMELTZER, S.; BARE, B. Brunner and Sudarth's textbook of medicalsurgical nursing. 7 ed. Philadelphia: J.B. Lippincott, 1992.

24. SPARKS, S.M.; TAYLOR, C.M. Nursing Diagnosis Reference Manual. 3 ed. Phyladelphia, Springhouse, 1995. Cap. 1, p. 24-359: Nursing Diagnosis.

25. TACAHASHI, D.M. Assistência de Enfermagem Pré-Hospitalar às Emergências - Um novo Desafio para a Enfermagem. R. Bras. Enferm., v. 44, n. 2/3, p. 113-15, 1991.

26. TAYLOR, LOUGHRAN, A. et al. Defining characteristics of the nursing diagnosis fear and anxiety: a validation study. Applied Nursing Research. v. 2, n. 4, p. 178-86, 1989.

27. TESTANI-DUFOUR, L.; CHAPPEL-AIKEN, L.; GUELDNER, S. Traumatic Brain injury: A Family Experience. Journal of Neuroscience Nursing. $v$. 24, n. 6, p. 317-23, 1992.

28. VERMELHO, L.L. Mortalidade de Jovens: Análise do período de 1930 1991. São Paulo, 1995. 184 p. Tese (Doutorado) - Faculdade de Saúde Pública, Universidade de São Paulo. 